\title{
Pilonidal Sinus in an Amputee
}

\author{
Maj F Khan \\ FRCS, RAMC
}

Specialist in Surgery

\section{DrR Fisher}

\section{$\mathrm{MB}, \mathrm{ChB}$}

Surgical House Officer

The Princess Alexandra Hospital, Royal Air Force, Wroughton, Swindon, Wiltshire SN4 OQJ

SUMMARY: A pilonidal sinus developed in the superio-medial aspect of the thigh of an above-knee amputee. This is an unusual site for the condition to develop. We suggest that the same aetiological factors that were responsible for the "Jeep Bottom" of World War II were also responsible for this problem in the amputation stump of a Falklands campaign casualty.

\section{Case Report}

A thirty-six year old hirsute soldier sustained a highvelocity gunshot wound during the Falklands campaign which resulted in an above-knee amputation. This was eventually managed with an ischial weight-bearing, suction-socket prosthesis, and he enjoyed good mobility. The original socket was made of aluminium, and gave him no trouble for four years. Three years ago the design was changed to a plastic cup.

Following the alteration he found that the socket suction decreased readily when he perspired in warm weather. This increased the friction element at the point of weight-bearing.

Eighteen months prior to admission he noticed a swelling in the superio-medial aspect of his right thigh. This was initially diagnosed as an infected, discharging sebaceous cyst. In the two months before arriving under our care his symptoms of discharge and discomfort grew steadily worse. The lesion was in a position where the edge of the cup pressed his thigh at the weight-bearing point.

On admission he presented with an inflamed lesion at this site (Fig 1). The presence of a sinus was noted, and the possibility of a pilonidal origin raised. After appropriate antibiotic therapy, the inflammation settled and a sinogram was obtained (Fig 2). This confirmed the presence of a three centimetre track.

In theatre, methylene blue dye was injected into the sinus to outline the track, and a probe inserted (Fig 3). The sinus was excised, the presence of a hair noted and the wound primarily sutured. Histological examination confirmed the diagnosis of a pilonidal sinus (Fig 4).

It is of interest to note that the patient had had a pilonidal sinus excised from his natal cleft in 1982, after having been wheelchair bound for several months.

\section{Discussion}

Pilonidal sinus does occur in positions other than the natal cleft, but such occurrences are rare. They have been noted at the umbilicus(1), on the penis(2),

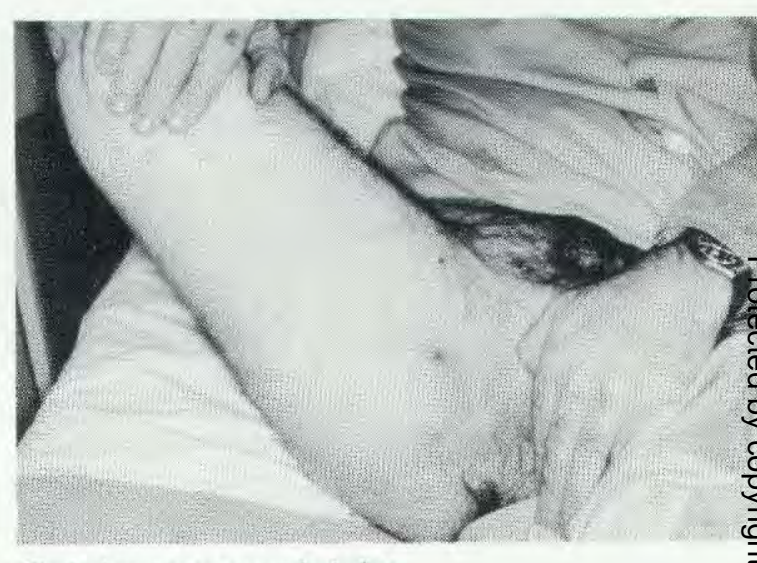

Fig 1. Appearance on admission.

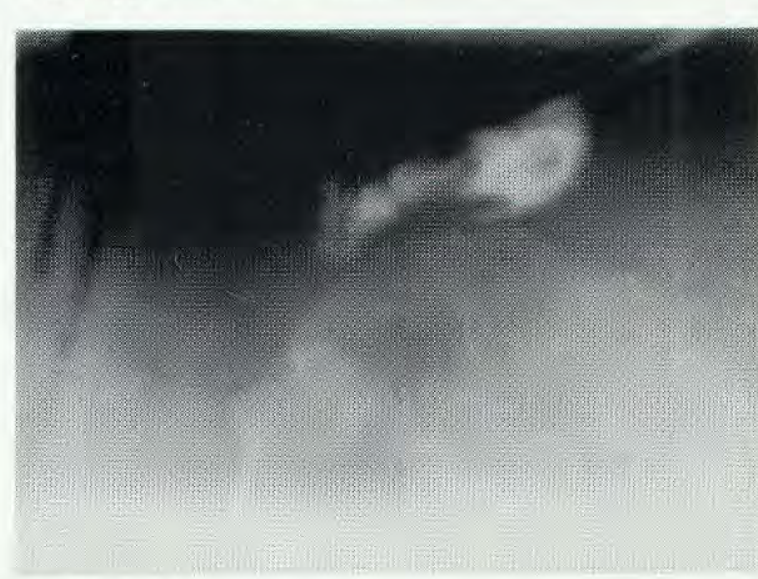

Fig 2. Sinogram.

prepuce(3), in the axilla(4) and in the interdigital web space of hairdressers(5). However, an English language literature search revealed no previous case of the condition in the limb stump of an amputee. 


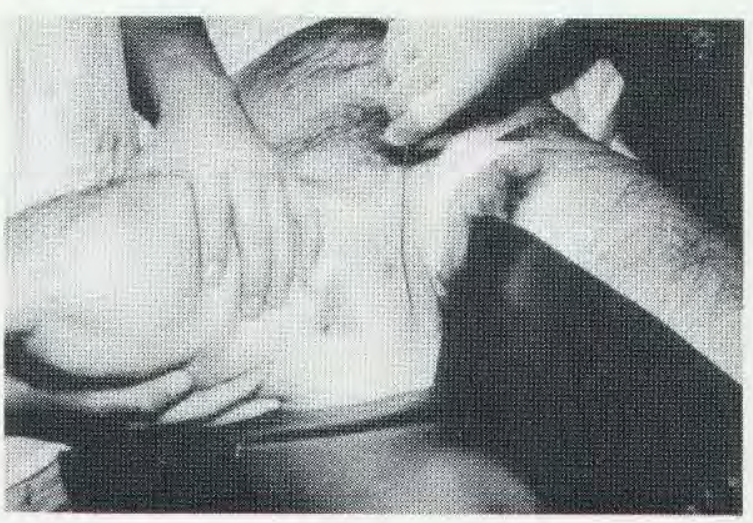

Fig 3. Probe in sinus in theatre.

If it is assumed that pressure, as in sitting(6), plays some part in the formation of a pilonidal sinus, then the weight-bearing site of the amputee is at increased risk of this occurring. It would be even more likely in an area where hair grows abundantly, and perspiration, friction and intermittent suction further increase the risk.

Often such lesions at other sites are allowed, after excision, to heal by secondary intention. However, we felt in this case healing by secondary intention would be liable to produce a scar less able to withstand the friction and pressure to which it will be subjected by the prosthesis.

Further, successful primary closure produces more rapid healing, reducing the period of limited mobility in the amputee. Guyuron et al recommended this for small, shallow pilonidal sinus(7), and it proved to be of value in this case.

\section{Conclusion}

A pilonidal sinus should be considered as a possible aetiology when investigating discharging and inflamed lesions in the pressured areas of amputees. Primary closure is to be preferred in these sites.

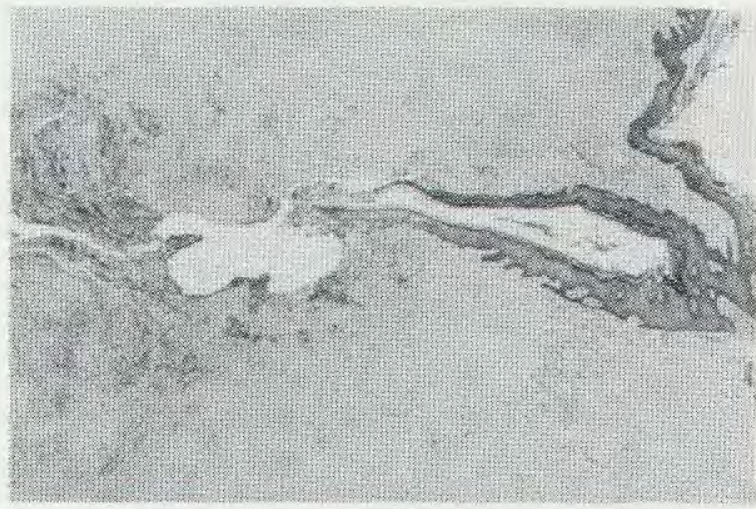

Fig 4. Histological appearance of a pilonidal sinus.

\section{Acknowledgement}

Our thanks go to Colonel M J Payne L/RAMC for allowing us to report this case and for his helpful advice in its presentation. We are also grateful to the library staff of the RAM College for their assistance with our search of the literature, and the Department of Photography and Medical Illustration of the College for 0 their help with the preparation of the photographs.

\section{REFERENCES}

1. Colapinto N D. Umbilical pilonidal sinus. Br J Surg $1977 \stackrel{\vec{\otimes}}{\overparen{D}}$ 64:494-495.

2. Fisher C, Peters L J, Witherow R O. Pilonidal sinus o the penis. J Urol 1976; 116:816-817.

3. Goudarzi H A, Mccoll I. Pilonidal sinus of the prepuce Br Med J 1976; 2:150.

4. Bailey and Loves Short Practice of Surgery, 20th Ed $\rightleftharpoons$ H K Lewis and Co Ltd, London. 1988, p 1139.

5. Browse N. Symptoms and Signs of Surgical Disease. Edward Arnold Publishers, 1978, p 387.

6. Clothier P R, HaYward I R. The natural history of the post-anal (pilonidal) sinus. Ann R Coll Surg 1984: 66: 201203.

7. Guyuron B, Dinner M I, Dowden R V. Excision and grafting in the treatment of recurrent pilonidal sinus disease. Surg Gyncol Obstet 1983; 156:201-204. 